\title{
Identification of novel biomarkers, MUC5AC, MUC1, KRT7, GAPDH, CD44 for gastric cancer
}

\author{
Jie Yang ${ }^{1}$ \\ Received: 17 February 2020 / Accepted: 10 March 2020 / Published online: 27 March 2020 \\ (c) The Author(s) 2020
}

\begin{abstract}
Gastric cancer (GC) is one of the most common malignant tumors in the world, and it is also the third largest cause of cancerrelated death in the world. As far as we know, no biomarker has been widely accepted for early diagnosis and prognosis prediction of gastric cancer. The purpose of this study is to find potential biomarkers to predict the prognosis of GC. The gene expression profiles of GSE2685 were downloaded from GEO database. Morpheus was used to calculate the differentially expressed genes (DEGs) between primary advanced gastric cancer tissues and noncancerous gastric tissues. The gene ontology (GO) and Kyoto Encyclopedia of Genes and Genomes pathway (KEGG) enrichment analyses were performed, and protein-protein interaction (PPI) network of DEGs was constructed. Kaplan-Meier Plotter was used to determine the overall survival (OS) outcomes of UC5AC, MUC1, KRT7, GAPDH, CD44, and GEPIA was used to determine the Pearson correlation analysis. In total, 710 DEGs were identified in GC, including 396 upregulated genes and 314 downregulated genes. GO enrichment revealed that they were mainly enriched in binding, catalytic activity, cellular process and cell. KEGG pathway revealed that they were mainly enriched in metabolic pathways, pathways in cancer and PI3K-Akt signaling pathway. MUC5AC, MUC1, KRT7, GAPDH, CD44 were identified from the PPI network. MUC5AC, MUC1, KRT7, GAPDH, CD44 were demonstrated to have prognostic value for patients with GC. MUC5AC, MUC1 exhibited low expression levels in GC tissues, $K R T 7, G A P D H, C D 44$ presented high expression levels in GC tissues. In particular, KRT7 is hardly expressed in normal gastric tissues. $M U C 5 A C$ and $M U C 1$ were negatively correlated with $G A P D H, C D 44$, respectively; and $G A P D H$ was positively correlated with $C D 44$ and KRT7, respectively. Moreover. MUC5AC, MUC1, KRT7, GAPDH, and CD44 are not only related to GC but also to apoptosis pathway. Results from the present study suggested that MUC5AC, MUCl, KRT7, $G A P D H, C D 44$ may represent novel prognostic biomarkers for GC.
\end{abstract}

Keywords Gastric cancer $\cdot$ Biomarker $\cdot$ Differentially expressed genes $\cdot$ Microarray

\section{Introduction}

Gastric cancer (GC) is one of the most common causes of tumor-related death worldwide. GC is the second largest malignant tumor in China [1,2]. The high incidence of $\mathrm{GC}$ is partly due to the widespread use of endoscopes. At present, the sensitivity and specificity of carcinoembryonic antigen (CEA) 19-9 in clinical application are limited, which leads to the unsatisfactory level of early diagnosis of GC [3-6]. Although progress has been made in the diagnosis and treatment of GC [7], the prognosis is still poor, and the

Jie Yang

yctcyangjie@163.com

1 Central Laboratory, Danyang People's Hospital of Jiangsu Province, Danyang, Jiangsu, China
5 year survival rate of patients with GC is less than $20 \%$. If there is no regional lymph node involvement, the survival rate of patients with GC is very high [8]. Unfortunately, GC is difficult to diagnose at an early stage. Therefore, people are very interested in finding prognostic markers for these potentially curable patients [9-13].

From molecular diagnosis to tumor molecular classification, from patient stratification to prognosis prediction, from new drug target discovery to tumor response prediction, high-throughput gene expression analysis platforms (such as microarrays) have been paid more and more attention. It is considered to be a promising tool in medical oncology [14-16]. In the past decade, microarray technology has been used to study the expression profiles of many genes in the carcinogenesis of GC, and hundreds of DEGs involved in different pathways, biological processes or molecular 
functions have been found $[17,18]$. However, a comparative analysis of DEGs in independent studies shows that the degree of overlap is relatively limited, and there is no reliable biomarker profile to distinguish cancer from normal tissue. Now, gene chip technology combined with bioinformatics analysis makes it possible to comprehensively analyze the changes of mRNA expression during the occurrence and development of GC. Hippo et al. used laser capture microdissection technique to collect tissue samples and detect DEGs in GC tissue and normal tissue, respectively [19]. However, the interaction between DEGs, especially the pathway in the interaction network, remains to be clarified.

In this study, we download raw data (GSE2685) from GEO as a center for storing and retrieving microarray data, and identify these data by comparing gene expression profiles between GC and normal tissues. Then, DEGs was screened by Morpheus software, and then gene ontology (GO) and pathway enrichment analysis were carried out. Through the analysis of its biological functions and pathways, we can further understand the occurrence and development of GC at the molecular level and explore potential biomarkers for diagnosis, prognosis and drug targets.

\section{Materials and methods}

\section{Microarray data}

The gene expression profiles of GSE2685 were downloaded from GEO database. GSE2685, which was based on Agilent GPL80 platform (Affymetrix Human Full Length HuGeneFL Array Hu6800), was submitted by Hippo et al. The GSE2685 dataset contained 30 samples, including 22 GC samples and 8 normal samples.

\section{Identification of DEGs}

Morpheus was applied to determine the differentially expressed genes (DEGs) in normal gastric tissues and GC tissues. Adjusted $P<0.01$ and $\mid \log$ fold change (FC) $\mid>1.5$ were set as cut-off values. A total of 710 DEGs were then identified, including 396 up-regulated and 314 down-regulated genes.

\section{Gene ontology and pathway enrichment analysis of DEGs}

Gene ontology analysis (GO) is a common useful method for annotating genes and gene products and for identifying characteristic biological attributes for high-throughput genome or transcriptome data. KEGG is a knowledge base for systematic analysis of gene functions, linking genomic information with higher-order functional information. In order to analyze the DEGs at the functional level, GO enrichment and KEGG pathway analysis were performed using DAVID online tool. $P<0.05$ was considered statistically significant.

\section{Integration of protein-protein interaction (PPI) network analysis}

Search tool for the retrieval of interacting genes (STRING) database is online tool designed to evaluate the protein-protein interaction (PPI) information. To evaluate the interactive relationships among DEGs, we mapped the DEGs to STRING, and only experimentally validated interactions with a combined score $>0.4$ were selected as significant. Then, PPI networks were constructed using the Cytoscape software. $P<0.05$ was considered to have significant differences.

\section{Expression levels, correlation and survival analysis}

The prognostic value of STATs mRNA expression was evaluated using Kaplan-Meier Plotter, which contained gene expression data and survival information of 1440 clinical GC patients. To analyze the Overall survival (OS) of patients with GC, patient samples were split into two groups by median expression (high vs. low expression) and assessed by a Kaplan-Meier survival plot, with the hazard ratio (HR) with $95 \%$ confidence intervals (CI) and log-rank p value. The genes associated with OS were applied for further analysis, including Pearson correlation analysis and analysis of expression levels in tumor and normal tissues using GEPIA.

\section{Results}

\section{Identification of DEGs}

There were 22 GC tissues and 8 normal gastric tissue samples analyzed in this study. Firstly, Morpheus was employed to identify DEGs using the following cut-off values: Adjusted $P<0.01$ and $\mid \log \mathrm{FCl}>1.5$. As a result, a total of 710 DEGs were identified, including 396 up-regulated and 314 down-regulated genes.

\section{GO term enrichment analysis}

We uploaded all DEGs to the online software DAVID to identify overrepresented GO categories and KEGG pathways. GO analysis results showed that up-regulated DEGs were significantly enriched in biological processes (BP), including cellular process, metabolic process, biological regulation and localization; the down-regulated DEGs were significantly enriched in cellular process, biological regulation, metabolic process and response to stimulus (Table 1). 
Table 1 Enrichment analysis of 117 differentially expressed genes in different tissues

\begin{tabular}{llll}
\hline Category & Gene function/term & Count & Percent (\%) \\
\hline A, Upregulated genes & & \\
MF & binding (GO:0005488) & 138 & 37.9 \\
MF & catalytic activity (GO:0003824) & 110 & 30.2 \\
MF & transcription regulator activity (GO:0140110) & 26 & 7.1 \\
BP & cellular process (GO:0009987) & 177 & 48.6 \\
BP & metabolic process (GO:0008152) & 113 & 31.0 \\
BP & biological regulation (GO:0065007) & 64 & 17.6 \\
BP & localization (GO:0051179) & 38 & 10.4 \\
CC & cell (GO:0005623) & 117 & 32.1 \\
CC & organelle (GO:0043226) & 103 & 28.3 \\
CC & protein-containing complex (GO:0032991) & 50 & 13.7 \\
CC & extracellular region (GO:0005576) & 41 & 11.3 \\
B, Down-regulated genes & & \\
MF & catalytic activity (GO:0003824) & 109 & 36.7 \\
MF & binding (GO:0005488) & 88 & 29.6 \\
MF & molecular transducer activity (GO:0060089) & 36 & 12.1 \\
BP & cellular process (GO:0009987) & 128 & 43.1 \\
BP & biological regulation (GO:0065007) & 80 & 26.9 \\
BP & metabolic process (GO:0008152) & 72 & 24.2 \\
BP & response to stimulus (GO:0050896) & 48 & 16.2 \\
CC & cell (GO:0005623) & 108 & 36.4 \\
CC & organelle (GO:0043226) & 51 & 17.2 \\
CC & membrane (GO:0016020) & 38 & 12.8 \\
\hline
\end{tabular}

For molecular function (MF), the up-regulated DEGs were enriched in binding, catalytic activity, and transcription regulator activity; the down-regulated DEGs were significantly enriched in catalytic activity, binding and molecular transducer activity (Table 1). In addition, GO cell component (CC) analysis also displayed that the up-regulated DEGs were significantly enriched in cell, organelle, protein-containing complex and extracellular region; the down-regulated DEGs were significantly enriched in cell, organelle and membrane (Table 1).

\section{KEGG pathway analysis}

Table 2 contains the most significantly enriched pathways of the up-regulated DEGs and down-regulated DEGs analyzed by KEGG analysis. The up-regulated DEGs were enriched in pathways in cancer, metabolic pathways, PI3K-Akt signaling pathway, human papillomavirus infection and focal adhesion, while the down-regulated DEGs were enriched in metabolic pathways, neuroactive ligand-receptor interaction, pathways in cancer, calcium signaling pathway, PI3K-Akt signaling pathway and cytokine-cytokine receptor interaction.
Table 2 Enriched KEGG pathways of differentially expressed genes

\begin{tabular}{llcc}
\hline Pathway ID & Name & Count & Percent (\%) \\
\hline $\begin{array}{l}\text { A, Up-regulated genes } \\
\text { hsa05200 }\end{array}$ & Pathways in cancer & 30 & 11.8 \\
hsa01100 & Metabolic pathways & 26 & 10.2 \\
hsa04151 & PI3K-Akt-signaling pathway & 24 & 9.4 \\
hsa05165 & Human papillomavirus infection & 21 & 8.2 \\
hsa04510 & Focal adhesion & 20 & 7.8 \\
B, Downregulated genes & & \\
hsa01100 & Metabolic pathways & 52 & 20.0 \\
hsa04080 & Neuroactive ligand-receptor & 23 & 8.8 \\
& interaction & 18 & 6.9 \\
hsa05200 & Pathways in cancer & 18 & 6.9 \\
hsa04020 & Calcium-signaling pathway & 13 & 5.0 \\
hsa04151 & PI3K-Akt-signaling pathway & 12 & 4.6 \\
hsa04060 & Cytokine-cytokine receptor & & \\
& interaction &
\end{tabular}

\section{Protein-protein interaction (PPI) network analysis}

This network contains known interactions from curated databases and those that were experimentally determined; predicted interactions containing gene neighborhood, gene fusions and gene cooccurrence; and text-mining, 
co-expression and protein homology. Based on the information in the STRING database, MUC5AC, MUC1, KRT7, GAPDH, CD44 were identified from the PPI network (Fig. 1).

\section{Survival curves, expression levels and correlation analysis}

MUC5AC, MUC1, KRT7, GAPDH, CD44 were demonstrated to have prognostic value for patients with GC. The MUC5AC, MUC1, KRT7, GAPDH, CD44 were significantly associated with overall survival (log-rank $P=1.9 \mathrm{e}-5,0.018,8.1 \mathrm{e}-6,1.1 \mathrm{e}-10$ and 0.011 , respectively) (Fig. 2a-e). The analysis of the five genes shows that low expression levels lead to better living conditions.

The genes MUC5AC, MUC1, KRT7, GAPDH, CD44 were then subjected to further analysis. Expression levels of the five genes are displayed in Fig. 3a-e. MUC5AC, $M U C 1$ exhibited low expression levels in GC tissues, $K R T 7, G A P D H, C D 44$ presented high expression levels in GC tissues. In particular, KRT7 is hardly expressed in normal gastric tissues.

Furthermore, Pearson correlation analyses between the genes are presented in Fig. 4a-d. Results revealed that MUC5AC was negatively correlated with GAPDH, CD44: GAPDH $(R=-0.077, P=0.054)$; CD44 $(R=-0.095$, $P=0.018$.); $M U C 1$ was also negatively correlated with $G A P D H, C D 44$ : GAPDH $(R=-0.13, P=0.001)$; CD44 $(R=-0.055, P=0.17)$. MUC5AC, MUC1, KRT7, each gene was positively correlated with the two other genes, and $G A P D H$ was positively correlated with $C D 44$ and $K R T 7$, respectively (all $R>0, P<0.05$ ).

\section{Discussion}

In this study, we investigated the potential prognostic association between GC and DEGs in GSE2685. The results showed that there were 710 differentially expressed genes between 8 normal gastric tissues and 22 gastric cancer tissues, of which 396 genes were up-regulated and 314 genes were down-regulated. MUC5AC, MUC1, KRT7, GAPDH, $C D 44$ has potential prognostic value for patients with GC. Moreover, these five genes are not only related to GC, but also to apoptosis pathway.

Gastric mucosal barrier protects gastric mucosa from hydrochloric acid and various harmful substances. MUC5AC is a gel-formed mucin, which is known as the main component of the gastric mucus layer [20-26]. MUC5AC is a wellknown marker of gastric differentiation, which is considered to be a very important prognostic indicator of GC and is often used in clinical evaluation [27-29]. It has been found that the expression of MUC5AC in stomach decreases with the development of intestinal metaplasia, and the expression of $M U C 5 A C$ is related to tumor stage: the expression level of MUC5AC in advanced GC is lower than that in early GC [30]. This is consistent with our analysis results that the expression of $M U C 5 A C$ in normal tissues is higher than that in GC tissues.

Keratin 7 is an intermediate filament protein, which is mainly expressed in epithelial and epithelial tumors. In GC, KRT7 has been identified as the target of long noncoding antisense RNA KRT7-AS and has been proved to be involved in the progression of gastric cancer [31]. KRT7 can promote the proliferation, migration and invasion of GC cells, and reduce the sensitivity to chemotherapy [32]. Interestingly, we found that $K R T 7$ was hardly expressed in normal tissues, but strongly expressed in GC tissues, and its
Fig. 1 Protein-protein interaction network of MUC5AC, MUC1, KRT7, GAPDH, CD44

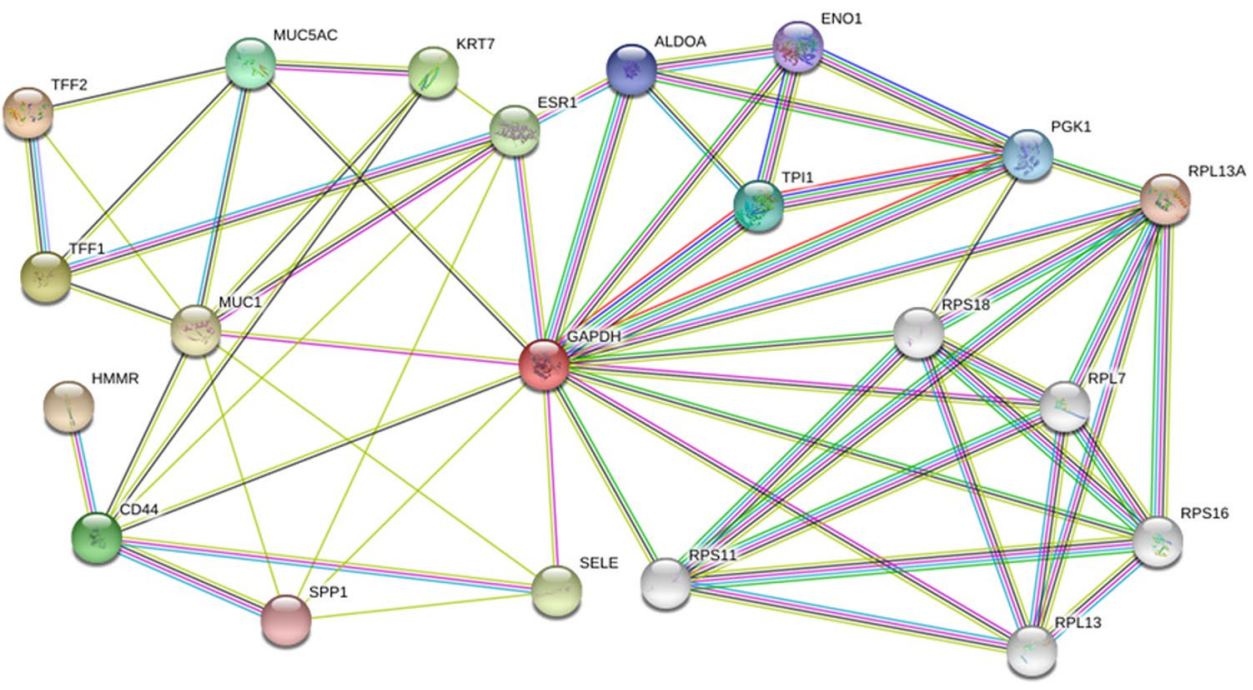



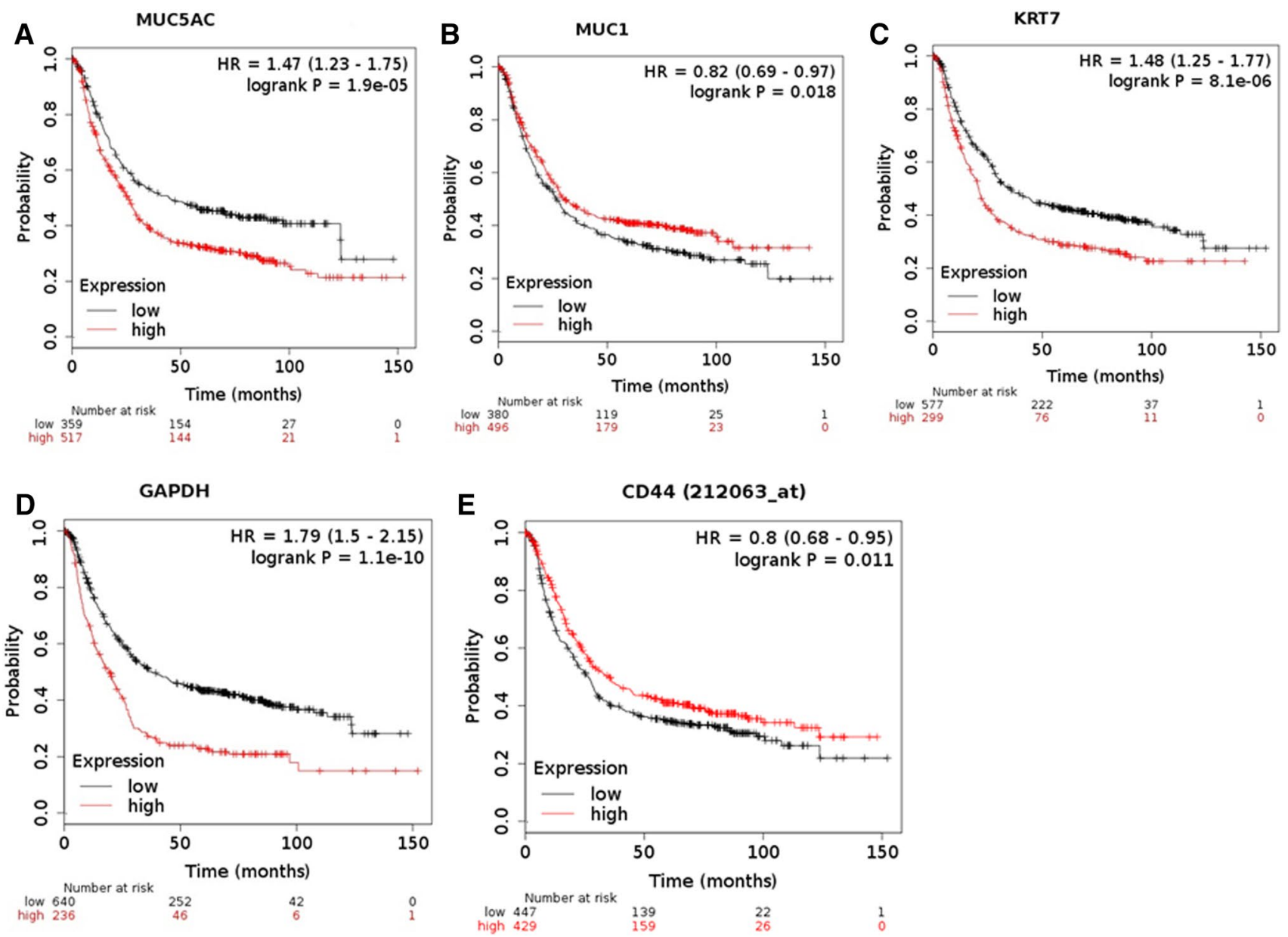

Fig. 2 Prognostic survival analysis of $M U C 5 A C(\mathbf{a}), M U C 1$ (b), KRT7 (c), GAPDH (d) and CD44 (e)

methylation is very strong. We speculate that methylation must play an important role in it.

It was found that stromal cells secrete glyceraldehyde 3-phosphate dehydrogenase (GAPDH). Extracellular GAPDH or its N-terminal domain inhibits the growth of gastric cancer cells, which has been confirmed in other cell systems [33-40]. They believe that the use of GAPDH to negatively regulate tumor growth may be a new anti-cancer strategy $[41,42]$. They believe that the use of GAPDH to negatively regulate tumor growth may be a new anti-cancer strategy [43-45]. Yamaji et al. reported that GAPDH is secreted by some cancer cells and can inhibit cell proliferation [46]. However, the inhibitory activity of GAPDH on the growth of cancer cells has not been reported. This is due to the sensitivity of cancer cells to GAPDH. They found that the N-terminal domain of GAPDH is necessary to exert its growth inhibitory activity. Interestingly, its growth inhibitory activity does not need the catalytic domain of the original enzyme activity. Unexpectedly, it has recently been reported that the N-terminal peptide of GAPDH has antifungal activity against Candida albicans through internalization. However, the immunofluorescence of anti-FLAG antibody under the condition of cell permeation showed that GAPDH was not incorporated into MKN-7 cells. Therefore, its mechanism is considered to be different. Our results showed that the expression of GAPDH in GC was higher than that in normal tissues, and it was negatively correlated with $M U C 5 A C$ and $M U C 1$, respectively.

In human $\mathrm{GC}$, the mechanism responsible for maintaining malignant stem cells in the tumor microenvironment is largely unknown [47-50]. Among the stem cell populations in the stomach, the cells that may be targeted and transformed into tumor initiation cells during chronic $\mathrm{Hel}$ icobacter pylori infection are those labeled by receptors 
A

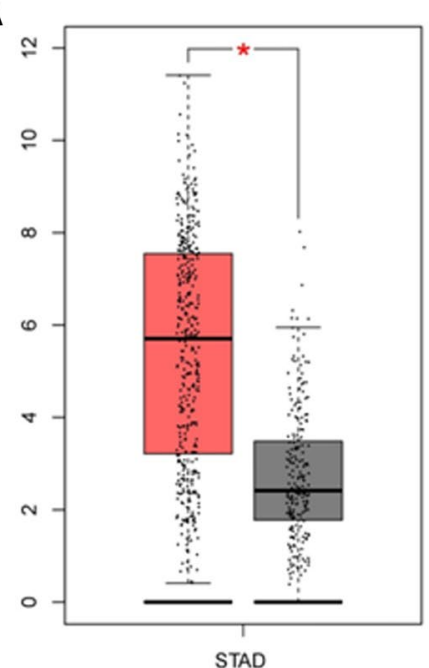

C

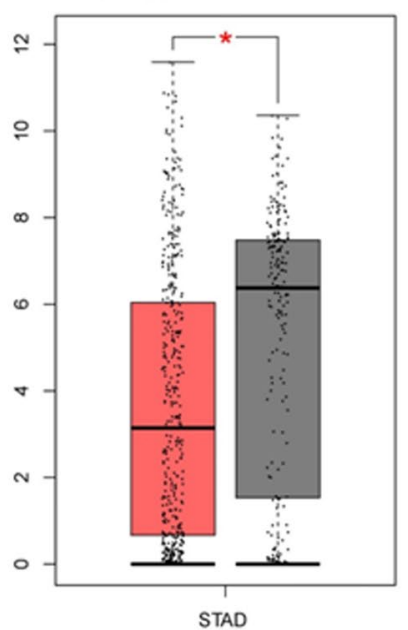

B

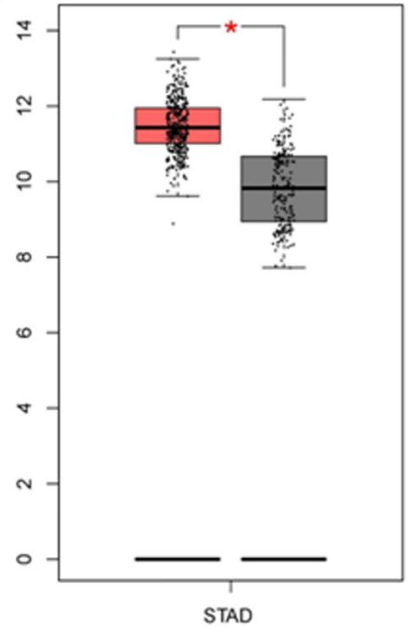

D

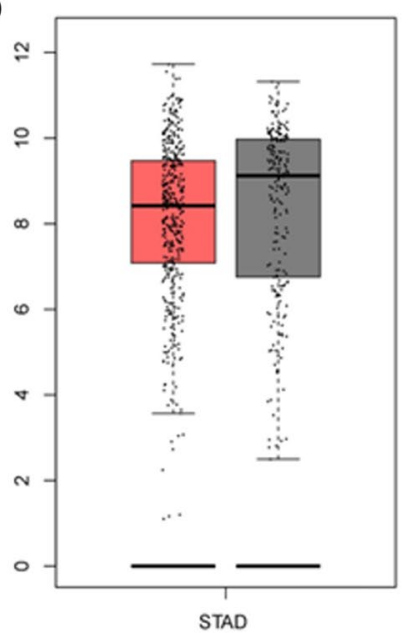

C

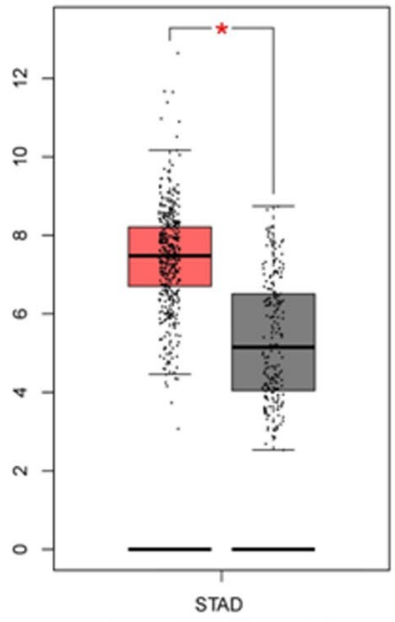

Fig. 3 Expression analysis of $M U C 5 A C, M U C 1, K R T 7, G A P D H$ and $C D 44$. Expression analysis of a KRT7, b GAPDH, c $C D 44, \mathbf{d} M U C 5 A C$ and $\mathbf{e} M U C 1$ in gastric normal and tumor tissues

on the surface of differentiated cluster 44 (CD44) cells [51]. Different from the typical CD44 standard isomers, CD44 variants $(\mathrm{CD} 44 \mathrm{v})$ are considered to be the key molecules in the process of malignant transformation, and their expression is highly restricted and specific $[52,53]$. In general, CD44v, is considered to be a marker of GC cells $[54,55]$, which help to increase resistance to chemotherapy or radiation-induced cell death [56-65]. Our results indicated that the expression of CD44 in GC was higher than that in normal tissues, and there was a positive correlation between $C D 44$ and $G A P D H$.
In conclusion, 710 DEGs were found in patients with gastric cancer in this study. These genes may function through binding, catalytic activity, cellular processes and cells, as well as metabolic pathways, cancer pathways and PI3KAkt signaling pathways. MUC5AC, MUCl, KRT7, GAPDH and $C D 44$ are not only related to gastric cancer, but also to apoptosis pathway, suggesting that MUC5AC, MUCl, KRT7, $G A P D H$ and $C D 44$ may be potential prognostic biomarkers of gastric cancer. In addition, $K R T 7, G A P D H$ and $C D 44$ may play a carcinogenic role in gastric cancer, while MUC5AC and $M U C 1$ may play a tumor inhibitory role. Further molecular biology experiments are needed to confirm the function of identified genes in gastric cancer, especially in metastasis and cancer progression, to guide the clinical direction. 

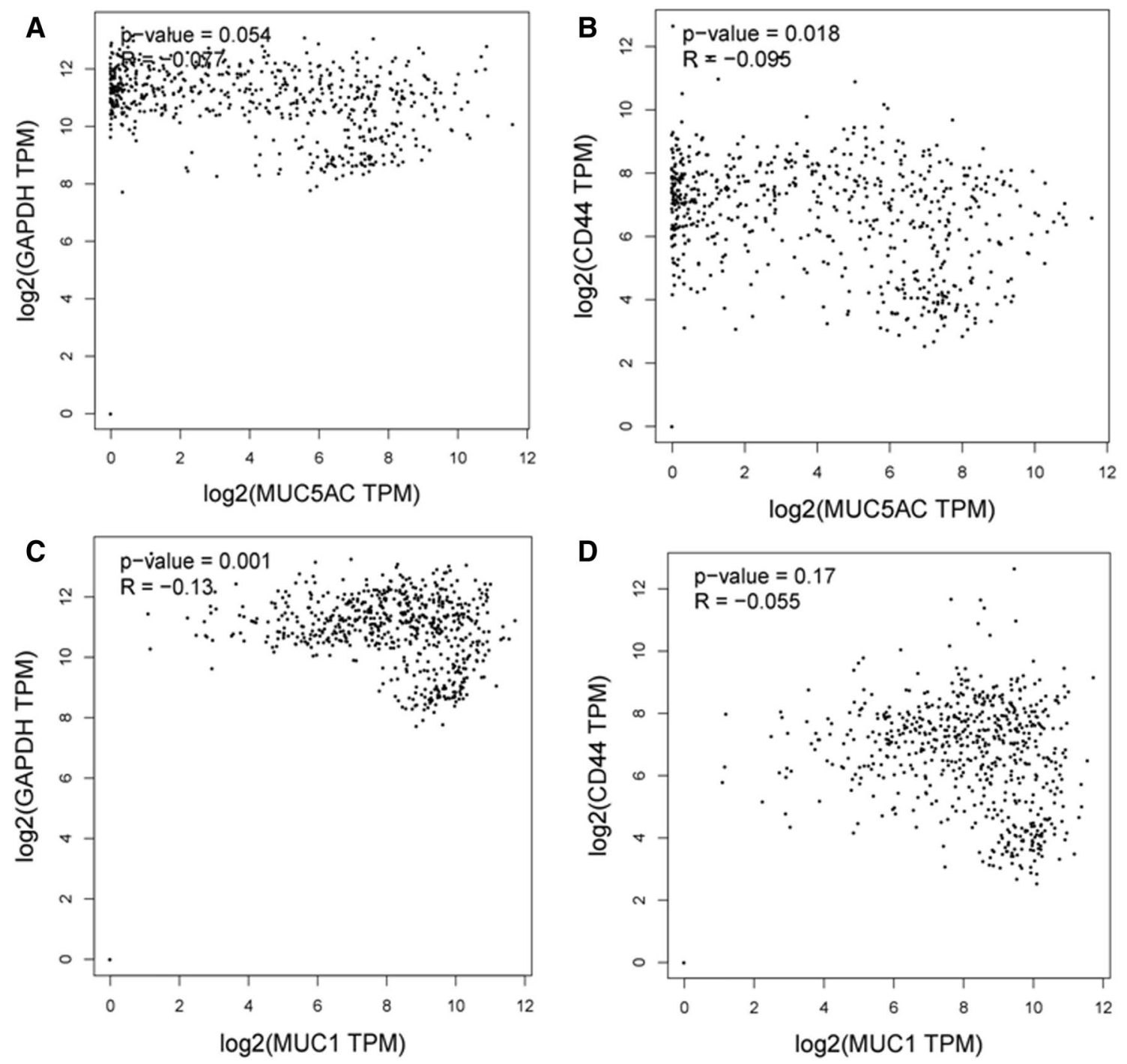

Fig. 4 Pearson correlation analyses of $M U C 5 A C, M U C 1, G A P D H$ and $C D 44$. MUC5AC was negatively correlated with $G A P D H, C D 44$ (a, b); $M U C 1$ was also negatively correlated with $G A P D H, C D 44(\mathbf{c}, \mathbf{d})$

\section{Compliance with ethical standards}

Conflict of interest The authors declare that there are no conflicts of interest.

Human participants and animal rights This article does not contain any studies with human participants or animals performed by any of the authors.

Open Access This article is licensed under a Creative Commons Attribution 4.0 International License, which permits use, sharing, adaptation, distribution and reproduction in any medium or format, as long as you give appropriate credit to the original author(s) and the source, provide a link to the Creative Commons licence, and indicate if changes were made. The images or other third party material in this article are included in the article's Creative Commons licence, unless indicated otherwise in a credit line to the material. If material is not included in the article's Creative Commons licence and your intended use is not permitted by statutory regulation or exceeds the permitted use, you will need to obtain permission directly from the copyright holder. To view a copy of this licence, visit http://creativecommons.org/licenses/by/4.0/.

\section{References}

1. Leung WK, Wu MS, Kakugawa Y, Kim JJ, Yeoh KG, Goh KL, et al. Screening for gastric cancer in Asia: current evidence and practice. Lancet Oncol. 2008;9(3):279-87. https://doi. org/10.1016/S1470-2045(08)70072-X.

2. Zhang G, Li J, Li S, Wang Y. Exploring spatial trends and influencing factors for gastric cancer based on Bayesian statistics: a case study of Shanxi, China. Int J Environ Res Public Health. 2018. https://doi.org/10.3390/ijerph15091824.

3. Ning S, Wei W, Li J, Hou B, Zhong J, Xie Y, et al. Clinical significance and diagnostic capacity of serum TK1, CEA, CA 19-9 and 
CA 72-4 levels in gastric and colorectal cancer patients. J Cancer. 2018;9(3):494-501. https://doi.org/10.7150/jca.21562.

4. Bluvshtein GA, Lysenko VG, Zakharova NB, Kitaev IV. Tumor markers p53, sFAS, FASL, CEA and CA 19-9 in evaluating the effectiveness of surgical and pharmaco nutritional treatment of patients with gastric cancer. Eksperimental'naia i Klinicheskaia Gastroenterologiia. 2012;2:41-9.

5. Kim DH, Oh SJ, Oh CA, Choi MG, Noh JH, Sohn TS, et al. The relationships between perioperative CEA, CA 19-9, and CA 72-4 and recurrence in gastric cancer patients after curative radical gastrectomy. J Surg Oncol. 2011;104(6):585-91. https://doi. org/10.1002/jso.21919.

6. Tian SB, Yu JC, Kang WM, Ma ZQ, Ye X, Cao ZJ, et al. Combined detection of CEA, CA 19-9, CA 242 and CA 50 in the diagnosis and prognosis of resectable gastric cancer. Asian Pac J Cancer Prev. 2014;15(15):6295-300. https://doi.org/10.7314/ apjcp.2014.15.15.6295.

7. Dilege E, Mihmanli M, Demir U, Ozer K, Bostanci O, Kaya C, et al. Prognostic value of preoperative CEA and CA 19-9 levels in resectable gastric cancer. Hepatogastroenterology. 2010;57(99-100):674-7.

8. Zhang LX, Wei ZJ, Xu AM, Zang JH. Can the neutrophil-lymphocyte ratio and platelet-lymphocyte ratio be beneficial in predicting lymph node metastasis and promising prognostic markers of gastric cancer patients? Tumor maker retrospective study. Int J Surg. 2018;56:320-7. https://doi.org/10.1016/j.ijsu.2018.06.037.

9. Yesseyeva G, Aikemu B, Hong H, Yu C, Dong F, Sun J, et al. Prefoldin subunits (PFDN1-6) serve as poor prognostic markers in gastric cancer. Biosci Rep. 2020. https://doi.org/10.1042/BSR20 192712.

10. Ahmed A. Prevalence of Her3 in gastric cancer and its association with molecular prognostic markers: a Saudi cohort based study. Libyan J Med. 2019;14(1):1574532. https://doi. org/10.1080/19932820.2019.1574532.

11. Feng F, Sun L, Liu Z, Liu S, Zheng G, Xu G, et al. Prognostic values of normal preoperative serum cancer markers for gastric cancer. Oncotarget. 2016;7(36):58459-69. https://doi.org/10.18632/ oncotarget.11248.

12. Liu X, Wu Z, Lin E, Li W, Chen Y, Sun X, et al. Systemic prognostic score and nomogram based on inflammatory, nutritional and tumor markers predict cancer-specific survival in stage II-III gastric cancer patients with adjuvant chemotherapy. Clin Nutr. 2019;38(4):1853-60. https://doi.org/10.1016/j.clnu.2018.07.015.

13. Lopes LO, Maues JH, Ferreira-Fernandes H, Yoshioka FK, Junior SCS, Santos AR, et al. New prognostic markers revealed by RNASeq transcriptome analysis after MYC silencing in a metastatic gastric cancer cell line. Oncotarget. 2019;10(56):5768-79. https ://doi.org/10.18632/oncotarget.27208.

14. Shen Y, Zhang J, Fu Z, Zhang B, Chen M, Ling X, et al. Gene microarray analysis of the circular RNAs expression profile in human gastric cancer. Oncol Lett. 2018;15(6):9965-72. https:// doi.org/10.3892/ol.2018.8590.

15. Takeno A, Takemasa I, Seno S, Yamasaki M, Motoori M, Miyata $\mathrm{H}$, et al. Gene expression profile prospectively predicts peritoneal relapse after curative surgery of gastric cancer. Ann Surg Oncol. 2010;17(4):1033-42. https://doi.org/10.1245/s10434-009-0854-1.

16. Wang $\mathrm{T}, \mathrm{Xu} \mathrm{Y}, \mathrm{Hou} \mathrm{P}$. Identifying novel biomarkers of gastric cancer through integration analysis of single nucleotide polymorphisms and gene expression profile. Int J Biol Markers. 2015;30(3):e321-e326326. https://doi.org/10.5301/jbm.5000145.

17. Xu ZY, Chen JS, Shu YQ. Gene expression profile towards the prediction of patient survival of gastric cancer. Biomed Pharmacother. 2010;64(2):133-9. https://doi.org/10.1016/j.bioph a.2009.06.021.

18. Yu CD, Xu SH, Mou HZ, Jiang ZM, Zhu CH, Liu XL. Gene expression profile differences in gastric cancer, pericancerous epithelium and normal gastric mucosa by gene chip. World J Gastroenterol. 2005;11(16):2390-7. https://doi.org/10.3748/wjg.v11. i16.2390.

19. Hippo Y, Taniguchi H, Tsutsumi S, Machida N, Chong JM, Fukayama M, et al. Global gene expression analysis of gastric cancer by oligonucleotide microarrays. Cancer Res. 2002;62(1):233-40.

20. Giraldi L, Michelazzo MB, Arzani D, Persiani R, Pastorino R, Boccia S. MUC1, MUC5AC, and MUC6 polymorphisms, Helicobacter pylori infection, and gastric cancer: a systematic review and meta-analysis. Eur J Cancer Prev. 2018;27(4):323-30. https ://doi.org/10.1097/CEJ.0000000000000348.

21. Wang C, Wang J, Liu Y, Guo X, Zhang C. MUC5AC upstream complex repetitive region length polymorphisms are associated with susceptibility and clinical stage of gastric cancer. PLoS ONE. 2014;9(6):e98327. https://doi.org/10.1371/journal.pone.0098327.

22. Park KK, Yang SI, Seo KW, Yoon KY, Lee SH, Jang HK, et al. Correlations of human epithelial growth factor receptor 2 overexpression with MUC2, MUC5AC, MUC6, p53, and clinicopathological characteristics in gastric cancer patients with curative resection. Gastroenterol Res Pract. 2015;2015:946359. https:// doi.org/10.1155/2015/946359.

23. Mori Y, Kataoka H, Miura Y, Kawaguchi M, Kubota E, Ogasawara $\mathrm{N}$, et al. Subcellular localization of ATBF1 regulates MUC5AC transcription in gastric cancer. Int J Cancer. 2007;121(2):241-7. https://doi.org/10.1002/ijc.22654.

24. Xu Y, Zhang L, Hu G. Potential application of alternatively glycosylated serum MUC1 and MUC5AC in gastric cancer diagnosis. Biologicals. 2009;37(1):18-25. https://doi.org/10.1016/j.biolo gicals.2008.08.002.

25. Shi D, Qiu XM, Yan XJ. The changes in MUC5AC expression in gastric cancer before and after Helicobacter pylori eradication. Clin Res Hepatol Gastroenterol. 2014;38(2):235-40. https://doi. org/10.1016/j.clinre.2013.06.008.

26. Shi D, Qiu XM, Bao YF. Effects of Helicobacter pylori infection on MUC5AC protein expression in gastric cancer. Future Oncol. 2013;9(1):115-20. https://doi.org/10.2217/fon.12.172.

27. Kim SM, Kwon CH, Shin N, Park DY, Moon HJ, Kim GH, et al. Decreased Muc5AC expression is associated with poor prognosis in gastric cancer. Int J Cancer. 2014;134(1):114-24. https://doi. org/10.1002/ijc. 28345

28. Zhang CT, He KC, Pan F, Li Y, Wu J. Prognostic value of Muc5AC in gastric cancer: a meta-analysis. World J Gastroenterol. 2015;21(36):10453-60. https://doi.org/10.3748/wjg.v21. i36.10453.

29. Zhou CJ, Zhang LW, Gao F, Zhang B, Wang Y, Chen DF, et al. Association analysis of common genetic variations in MUC5AC gene with the risk of non-cardia gastric cancer in a Chinese population. Asian Pac J Cancer Prev. 2014;15(10):4207-10. https://doi. org/10.7314/apjcp.2014.15.10.4207.

30. Jiang K, Liu H, Xie D, Xiao Q. Differentially expressed genes ASPN, COL1A1, FN1, VCAN and MUC5AC are potential prognostic biomarkers for gastric cancer. Oncol Lett. 2019;17(3):3191-202. https://doi.org/10.3892/ol.2019.9952.

31. Liu BL, Qin JJ, Shen WQ, Liu C, Yang XY, Zhang XN, et al. FOXA1 promotes proliferation, migration and invasion by transcriptional activating KRT7 in human gastric cancer cells. J Biol Regul Homeost Agents. 2019;33(4):1041-50.

32. Huang B, Song JH, Cheng Y, Abraham JM, Ibrahim S, Sun Z, et al. Long non-coding antisense RNA KRT7-AS is activated in gastric cancers and supports cancer cell progression by increasing KRT7 expression. Oncogene. 2016;35(37):4927-36. https://doi. org/10.1038/onc.2016.25.

33. Butera G, Mullappilly N, Masetto F, Palmieri M, Scupoli MT, Pacchiana R, et al. Regulation of autophagy by nuclear GAPDH and its aggregates in cancer and neurodegenerative disorders. Int J Mol Sci. 2019. https://doi.org/10.3390/ijms20092062. 
34. Butera G, Pacchiana R, Mullappilly N, Margiotta M, Bruno $\mathrm{S}$, Conti $\mathrm{P}$, et al. Mutant p53 prevents GAPDH nuclear translocation in pancreatic cancer cells favoring glycolysis and 2-deoxyglucose sensitivity. Biochim Biophys Acta Mol Cell Res. 2018;1865(12):1914-23. https://doi.org/10.1016/j.bbamc r.2018.10.005.

35. Caradec J, Sirab N, Revaud D, Keumeugni C, Loric S. Is GAPDH a relevant housekeeping gene for normalisation in colorectal cancer experiments? Br J Cancer. 2010;103(9):1475-6. https://doi. org/10.1038/sj.bjc.6605851.

36. Ganapathy-Kanniappan S, Geschwind JF, Kunjithapatham R, Buijs M, Vossen JA, Tchernyshyov I, et al. Glyceraldehyde3-phosphate dehydrogenase (GAPDH) is pyruvylated during 3-bromopyruvate mediated cancer cell death. Anticancer Res. 2009;29(12):4909-18.

37. Hansen CN, Ketabi Z, Rosenstierne MW, Palle C, Boesen HC, Norrild B. Expression of CPEB, GAPDH and U6snRNA in cervical and ovarian tissue during cancer development. APMIS. 2009;117(1):53-9. https://doi.org/10.111 1/j.1600-0463.2008.00015.x.

38. Hjerpe E, Egyhazi Brage S, Carlson J, Frostvik Stolt M, Schedvins $\mathrm{K}$, Johansson H, et al. Metabolic markers GAPDH, PKM2, ATP5B and BEC-index in advanced serous ovarian cancer. BMC Clin Pathol. 2013;13(1):30. https://doi.org/10.1186/1472-6890-13-30.

39. Jung DW, Kim WH, Seo S, Oh E, Yim SH, Ha HH, et al. Chemical targeting of GAPDH moonlighting function in cancer cells reveals its role in tubulin regulation. Chem Biol. 2014;21(11):1533-45. https://doi.org/10.1016/j.chembiol.2014.08.017.

40. Zhong XY, Yuan XM, Xu YY, Yin M, Yan WW, Zou SW, et al. CARM1 methylates GAPDH to regulate glucose metabolism and is suppressed in liver cancer. Cell Rep. 2018;24(12):3207-23. https://doi.org/10.1016/j.celrep.2018.08.066.

41. Kim SH, Park WS, Lee SJ, Choi MK, Yeon SM, Joo JN, et al. The quantified level of circulating prostate stem cell antigen mRNA relative to GAPDH level is a clinically significant indictor for predicting biochemical recurrence in prostate cancer patients after radical prostatectomy. Biomed Res Int. 2015;2015:292454. https ://doi.org/10.1155/2015/292454.

42. Kunjithapatham R, Ganapathy-Kanniappan S. GAPDH with $\mathrm{NAD}(+)$-binding site mutation competitively inhibits the wildtype and affects glucose metabolism in cancer. Biochim Biophys Acta Gen Subj. 2018;1862(12):2555-633. https://doi. org/10.1016/j.bbagen.2018.08.001.

43. Nicholls C, Pinto AR, Li H, Li L, Wang L, Simpson R, et al. Glyceraldehyde-3-phosphate dehydrogenase (GAPDH) induces cancer cell senescence by interacting with telomerase RNA component. Proc Natl Acad Sci USA. 2012;109(33):13308-13. https ://doi.org/10.1073/pnas.1206672109.

44. Soltany-Rezaee-Rad M, Mottaghi-Dastjerdi N, Setayesh N, Roshandel G, Ebrahimifard F, Sepehrizadeh Z. Overexpression of FOXO3, MYD88, and GAPDH identified by suppression subtractive hybridization in esophageal cancer is associated with autophagy. Gastroenterol Res Pract. 2014;2014:185035. https:// doi.org/10.1155/2014/185035.

45. Zhang JY, Zhang F, Hong CQ, Giuliano AE, Cui XJ, Zhou GJ, et al. Critical protein GAPDH and its regulatory mechanisms in cancer cells. Cancer Biol Med. 2015;12(1):10-22. https://doi. org/10.7497/j.issn.2095-3941.2014.0019.

46. Kawada M, Inoue H, Ohba S, Yoshida J, Masuda T, Yamasaki $\mathrm{M}$, et al. Stromal cells positively and negatively modulate the growth of cancer cells: stimulation via the PGE2-TNFalpha-IL-6 pathway and inhibition via secreted GAPDH-E-cadherin interaction. PLoS ONE. 2015;10(3):e0119415. https://doi.org/10.1371/ journal.pone.0119415.

47. Tongtawee T, Wattanawongdon W, Simawaranon T, Kaewpitoon S, Kaengpenkae S, Jintabanditwong N, et al. Expression of cancer stem cell marker CD44 and its polymorphisms in patients with chronic gastritis, precancerous gastric lesion, and gastric cancer: a cross-sectional multicenter study in Thailand. Biomed Res Int. 2017;2017:4384823. https://doi.org/10.1155/2017/4384823.

48. Szczepanik A, Sierzega M, Drabik G, Pituch-Noworolska A, Kolodziejczyk P, Zembala M. CD44(+) cytokeratin-positive tumor cells in blood and bone marrow are associated with poor prognosis of patients with gastric cancer. Gastric Cancer. 2019;22(2):264-72. https://doi.org/10.1007/s10120-018-0858-2.

49. Sun M, Zhou W, Zhang YY, Wang DL, Wu XL. CD44(+) gastric cancer cells with stemness properties are chemoradioresistant and highly invasive. Oncol Lett. 2013;5(6):1793-8. https://doi. org/10.3892/ol.2013.1272.

50. Senel F, Kokenek Unal TD, Karaman H, Inanc M, Aytekin A. Prognostic value of cancer stem cell markers CD44 and ALDH1/2 in gastric cancer cases. Asian Pac J Cancer Prev. 2017;18(9):252731. https://doi.org/10.22034/APJCP.2017.18.9.2527.

51. Zavros Y. Initiation and maintenance of gastric cancer: a focus on CD44 variant isoforms and cancer stem cells. Cell Mol Gastroenterol Hepatol. 2017;4(1):55-63. https://doi.org/10.1016/j.jcmgh .2017.03.003.

52. Yamaguchi A, Saito M, Gio T, Iida A, Takeuchi K, Hirose K, et al. Expression of CD44 variant exons $8-10$ in gastric cancer. Jpn J Cancer Res. 1995;86(12):1166-71. https://doi. org/10.1111/j.1349-7006.1995.tb03310.x.

53. Setala L, Lipponen P, Tammi R, Tammi M, Eskelinen M, Alhava $\mathrm{E}$, et al. Expression of CD44 and its variant isoform v3 has no prognostic value in gastric cancer. Histopathology. 2001;38(1):1320. https://doi.org/10.1046/j.1365-2559.2001.01038.x.

54. Go SI, Ko GH, Lee WS, Kim RB, Lee JH, Jeong SH, et al. CD44 variant 9 serves as a poor prognostic marker in early gastric cancer, but not in advanced gastric cancer. Cancer Res Treat. 2016;48(1):142-52. https://doi.org/10.4143/crt.2014.227.

55. Go SI, Ko GH, Lee WS, Lee JH, Jeong SH, Lee YJ, et al. The use of CD44 variant 9 and $\mathrm{Ki}-67$ combination can predicts prognosis better than their single use in early gastric cancer. Cancer Res Treat. 2019;51(4):1411-9. https://doi.org/10.4143/crt.2018.663.

56. Yong CS, Ou Yang CM, Chou YH, Liao CS, Lee CW, Lee CC. CD44/CD24 expression in recurrent gastric cancer: a retrospective analysis. BMC Gastroenterol. 2012;12:95. https://doi. org/10.1186/1471-230X-12-95.

57. Yoon C, Park DJ, Schmidt B, Thomas NJ, Lee HJ, Kim TS, et al. CD44 expression denotes a subpopulation of gastric cancer cells in which Hedgehog signaling promotes chemotherapy resistance. Clin Cancer Res. 2014;20(15):3974-88. https://doi. org/10.1158/1078-0432.CCR-14-0011.

58. Yu D, Shin HS, Choi G, Lee YC. Proteomic analysis of CD44(+) and CD44(-) gastric cancer cells. Mol Cell Biochem. 2014;396(12):213-20. https://doi.org/10.1007/s11010-014-2156-6.

59. Zhang C, Li C, He F, Cai Y, Yang H. Identification of CD44+CD24+ gastric cancer stem cells. J Cancer Res Clin Oncol. 2011;137(11):1679-86. https://doi.org/10.1007/s0043 2-011-1038-5.

60. Zhang D, Jia H, Wang Y, Li WM, Hou YC, Yin SW, et al. A CD44 specific peptide developed by phage display for targeting gastric cancer. Biotechnol Lett. 2015;37(11):2311-20. https://doi. org/10.1007/s10529-015-1896-z.

61. Zeng JF, Ma XQ, Wang LP, Wang W. MicroRNA-145 exerts tumor-suppressive and chemo-resistance lowering effects by targeting CD44 in gastric cancer. World J Gastroenterol. 2017;23(13):2337-455. https://doi.org/10.3748/wjg.v23.i13.2337.

62. Yoo $\mathrm{CH}$, Noh $\mathrm{SH}$. The serum assay of soluble CD44 standard, CD44 variant 5, and CD44 variant 6 in patients with gastric cancer. Cancer Res Treat. 2003;35(1):3-8. https://doi.org/10.4143/ crt.2003.35.1.3. 
63. Yang Z, Luo H, Cao Z, Chen Y, Gao J, Li Y, et al. Dual-targeting hybrid nanoparticles for the delivery of SN38 to Her2 and CD44 overexpressed human gastric cancer. Nanoscale. 2016;8(22):11543-58. https://doi.org/10.1039/c6nr01749e.

64. Yang F, Zheng Z, Xue X, Zheng L, Qin J, Li H, et al. Targeted eradication of gastric cancer stem cells by CD44 targeting USP22 small interfering RNA-loaded nanoliposomes. Future Oncol. 2019;15(3):281-95. https://doi.org/10.2217/fon-2018-0295.

65. Yamakawa Y, Kusuhara M, Terashima M, Kinugasa Y, Sugino T, Abe M, et al. CD44 variant 9 expression as a predictor for gastric cancer recurrence: immunohistochemical and metabolomic analysis of surgically resected tissues. Biomed Res. 2017;38(1):41-52. https://doi.org/10.2220/biomedres.38.41.

Publisher's Note Springer Nature remains neutral with regard to jurisdictional claims in published maps and institutional affiliations. 